\title{
Optical coherence tomography - a review of the principles and contemporary uses in retinal investigation
}

Eye (2004) 18, 561-570. doi:10.1038/sj.eye.6700729 Published online 6 February 2004

\section{Introduction}

One of the most exciting developments in ophthalmic imaging in recent years is optical coherence tomography (OCT). This technique picks up where the resolution of ultrasound leaves off, offering an entirely new spectrum of high-resolution, cross-sectional images of the retina, vitreous, choroid, and optic nerve. ${ }^{1}$ Imaging of the anterior segment is also possible..$^{2-4}$ In the posterior segment, OCT is evolving as a noninvasive investigation in the place of, or complementary to, fluorescein angiography. This article aims to give the reader an understanding of the principles involved in OCT, an overview of the appearances of the commonly encountered conditions, and a description of the contemporary uses for OCT in retinal investigation. There are currently only a few OCT machines installed in the United Kingdom, but with increasing awareness of the potential benefits of OCT imaging, clinicians should be able to refer patients for imaging at a local centre and then manage their own patients on the resulting diagnosis or measurement.

\section{Principles}

Standard ultrasound depends on reflection of high-frequency sound waves (in the order of $10 \mathrm{MHz}$ travelling at $1500 \mathrm{~m} / \mathrm{s}$ in water) and is limited to a resolution of about $150 \mu \mathrm{m}$. OCT uses reflection of short coherence length light (usually $830 \mathrm{~nm}$ wavelength at a speed of $3 \times 10^{8} \mathrm{~m} / \mathrm{s}$ ) and results in resolution in the order of $10 \mu \mathrm{m}$. Although high-resolution

D Thomas ${ }^{1}$ and G Duguid ${ }^{2}$

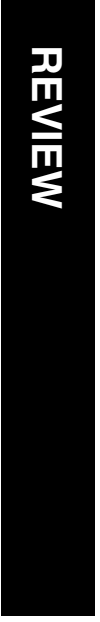

ultrasound systems are available allowing up to $20 \mu \mathrm{m}$ resolution, their penetration in tissue is limited to only $4-5 \mathrm{~mm}$. The clear media of the eye has lent itself to noncontact, noninvasive imaging by OCT, with imaging of other body tissues such as trachea, ${ }^{5}$ uterus, ${ }^{6}$ bladder, ${ }^{7}$ gastrointestinal tract, ${ }^{8}$ and peripheral vasculature ${ }^{9}$ requiring endoscopy to deliver light. In these organs, it is possible to obtain an 'optical biopsy' of $10 \mu \mathrm{m}$ resolution in vivo by placing the probe adjacent to the wall of a hollow viscus, ${ }^{10}$ with obvious potential in the early diagnosis of internal tumours.

The commercially available OCT machine from Humphrey Instruments Ltd (San Leandro, CA, USA), was developed by a team of bioengineers and ophthalmologists at the Massachusetts Institute of Technology, ${ }^{11}$ and is currently the only machine in clinical use. The OCT machine consists of a scanner attached to a slit-lamp, a video monitor, a computer, and a printer. Following its release in 1995, the product was rebranded as OCT 2 in 2001 when the hardware was ergonomically improved resulting in a smaller equipment footprint and the patient sitting opposite rather than perpendicular to the examiner. However, the images from OCT 1 and OCT 2 are similar and the term 'OCT' in this article refers to OCT 1 and OCT 2. OCT 3, released in 2002, produces much higher resolution images $(<8 \mu \mathrm{m})$, and offers other features such as improved ease of operation and faster image capture and processing. However the principle by which the machine functions is unchanged. Ultra-highresolution OCT is in development, and although images have been published, ${ }^{12,13}$ the equipment is not commercially available.
'St Thomas' Hospital Lambeth Palace Road London, UK

${ }^{2}$ The Western Eye Hospital Marylebone Road

London, UK

Correspondence: G Duguid The Western Eye Hospital Marylebone Road London NW1 5YE, UK Tel: +44 2076167666 Fax: + 44204864757

E-mail: g.duguid@ thelondonclinic.co.uk

Proprietary interest: None

Funding: D Thomas was funded by Guy's and St Thomas' Special Trustees Grant and Eli Lilly Diabetes Research Grant 
Posterior segment imaging is achieved by projecting light from a superluminescent diode via a slit-lamp and integrated $+78 \mathrm{D}$ biomicroscopy lens onto the retina, and acquiring an image via a computer. The incident light beam of 200 microwatts $(\mu \mathrm{W})$ is reflected at the interface between each ocular structure, and the time taken for the reflection enables the distance and the relative position of the structures to be calculated by comparison to a reference beam using interferometry (Figure 1).

A fibre-optic Michaelson interferometer splits lowcoherence light into two beams using a partially reflective mirror. The reference beam is reflected by the reference mirror towards a detector. The transmitted optical beam passes into the eye and is reflected from the various ocular structures back towards the beam splitter as the measurement beam. At the beam splitter, a single reference echo and a complex measurement echo combine producing optical interference, which is detected by a photoelectric cell. By moving the position of the reference mirror, the waveform of the interference pattern from the measurement beam can be varied and analysed electronically by the detector. Thus the interferometer measures the time delay of the optical reflections from the intraocular structures. ${ }^{1,14}$

The reflected signal is thus an A-scan of a small crosssection of the eye, and the intensities of the various signal returns are converted into a false-colour rainbow scale starting with black and the blue end of the spectrum, progressing through green, yellow, red to white in increasing order of reflectivity. If the axis of the scan is moved horizontally, sequential sections can be aligned to create a composite cross-sectional colour image. Typically, one posterior segment OCT 1 or OCT 2 image is composed of 100 individual colour-coded A-scans aligned with respect to the bright reflection from the retinal pigment epithelium (RPE). OCT 3 images are

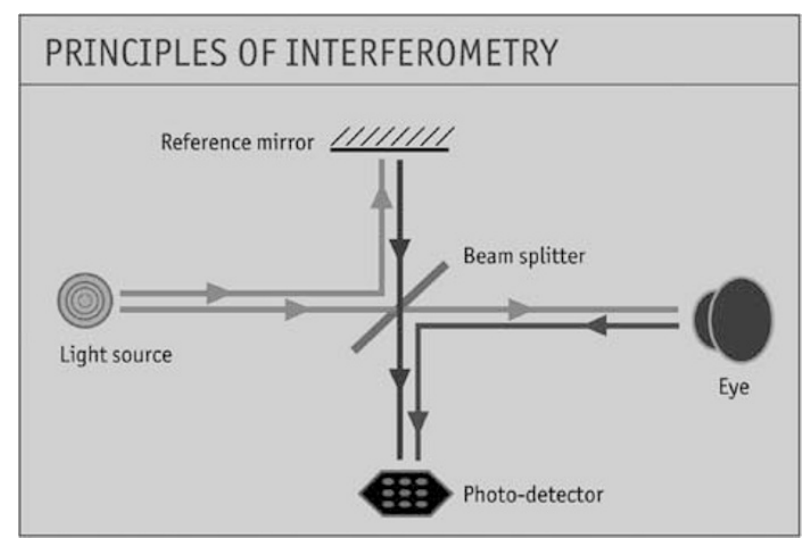

Figure 1 Ray diagram showing the principle of interferometry used in OCT. composed of 512 A-scans, hence yielding higher resolution. It is important to realise that each interface in the OCT image represents a difference in optical properties and not necessarily a different anatomical structure, although early reports suggest that OCT 3 may be capable of demonstrating greater anatomical detail than OCT 1 and OCT 2.

Various scan patterns can be used, including single lines of differing length and orientation (with shorter scans having a higher resolution), lines arranged radially centred on the same point, annular scans of varying diameters and sequential parallel lines. Each OCT scan is captured individually and takes about $1 \mathrm{~s}$ to acquire. OCT 3 can acquire up to six scans simultaneously in $1 \mathrm{~s}$. The scan settings can be memorised allowing exactly the same scan position to be used on a follow-up examination. The field of view is limited to about $30^{\circ}$, and although scan resolution may be limited by media opacities, it is still possible to capture an image through moderate vitreous haemorrhage or cataract.

\section{Normal appearances}

The normal OCT image of the posterior pole centred on fixation is shown in Figure 2a and a normal OCT 3 image is shown in Figure 2b. A hyper-reflective (red) line in the mid-thickness of the trace is a central reference point and represents the RPE and choriocapillaris. Above (anterior to) this is a layer of lower reflectivity (yellow-green), which is the retina. The foveal depression is clearly visible, as is the optic disc. The retinal layer is heterogeneous on OCT, and the intraretinal layers have been described by some authors, for example, Toth $e a^{15}$ described the nerve fibre layer as a hyper-reflective (red) layer, which is usually visible where this layer is thickest, nasal to the fovea on horizontal sections and superior and inferior to the fovea in vertical sections, but which is more variably recognisable temporal to the fovea. Chauhan and Marshall ${ }^{14}$ have questioned this however, and it is probably only acceptable to describe the retinal thickness as the image lying between the anterior surface of the RPE and the vitreoretinal interface. The normal foveal thickness measured by OCT is approximately $160 \mu \mathrm{m} .{ }^{16,17}$ Early images presented from ultra-highresolution OCT technology, which is in development, appear to resolve the retina into its individual layers, including the external limiting membrane. OCT 3 has an intermediate resolution but is a significant step towards achieving a 'noninvasive optical biopsy'.

The posterior hyaloid face may be visible as a thin hyper-reflective (red-white) structure against the dark hyporeflective vitreous cavity, and whether it is completely or partially detached is usually readily apparent. However, this layer is not discernable if there is 

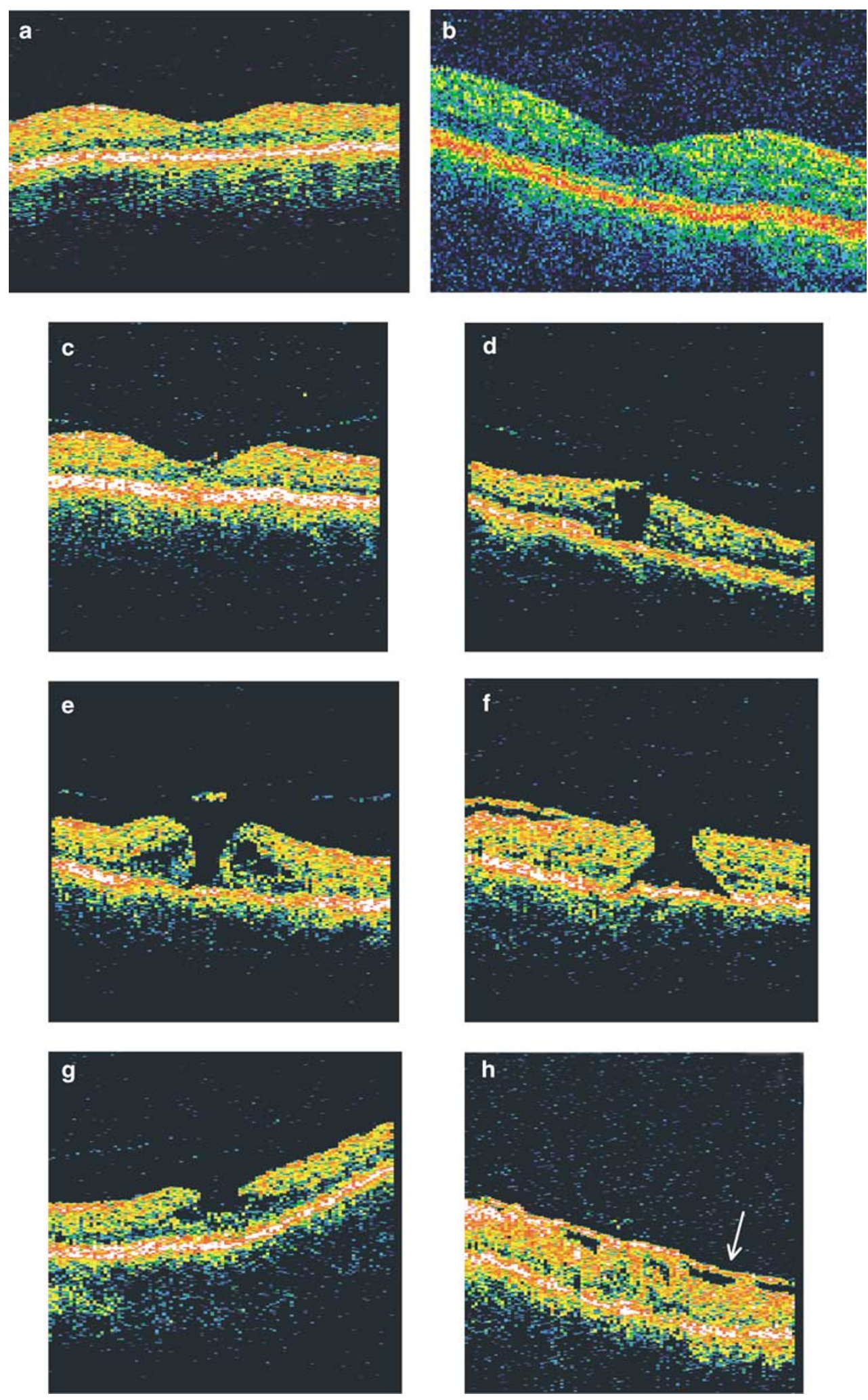

Figure 2 (a, b) OCT and OCT3 images of the normal posterior pole centred on fixation. (c) Stage 1 macular hole showing an intrafoveal split with the posterior hyaloid attached to the foveal centre. (d) Stage 2 macular hole showing the cyst roof opening eccentrically with the hyaloid still attached and full-thickness separation of the retina. (e) Stage 3 operculated macular hole. (f) Stage 4 macular hole with an associated epiretinal membrane. (g) A lamellar hole is seen on OCT as a partial-thickness retinal defect with concave lateral edges and a layer of retinal reflectivity in its base. (h) An epiretinal membrane (white arrow) separated from the retina at several points. 
no vitreoretinal separation. ${ }^{15}$ Deep to the RPE/ choriocapillaris layer the signal is weak due to attenuation. However, the anterior choroid is visible as a hyporeflective (green) layer and choroidal blood vessels may be visible as even more hyporeflective (dark) structures within this.

\section{Applications}

With the normally clear optical media, OCT is readily applicable to ophthalmic imaging. The cross-sectional image obtained not only allows a diagnosis to be made, for example, in macular holes, pseudoholes, lamellar holes, ${ }^{18,19}$ but since the coordinates and settings of each scan can be memorised, the same area of retina can be scanned on different occasions allowing monitoring of the condition. In addition, measurement of retinal thickness is possible allowing quantitative follow-up. This is particularly useful in monitoring treatment for macular oedema or resolution of central serous retinopathy. OCT measurements of retinal thickness have been found to be highly reproducible both between observers and between visits in normal subjects and in diabetic patients. ${ }^{3,17,20}$ Massin et al found a reproducibility of $\pm 5 \%$ for healthy subjects and $\pm 6 \%$ for diabetic subjects in all ETDRS areas and a repeatability of 7 and $21 \mu \mathrm{m}$ in healthy and diabetic subjects, respectively.

The OCT image may show abnormalities of the vitreomacular interface and the profile of the inner retinal boundary. Intraretinal abnormalities may result from abnormal reflectivity due to changes in the optical properties of retinal tissue morphology. Hyperreflectivity in the retina or choroid may result from scar tissue, inflammatory infiltrates, hard exudates, or haemorrhages. Furthermore, if these lesions are dense, a degree of masking of the signal returned from the underlying tissues may result from the attenuation and scatter of the signal. Hyporeflectivity is usually due to fluid accumulation such as macular oedema or subretinal fluid, the location of which is usually readily distinguishable and useful in the differential diagnosis of CSR, pigment epithelial detachment, and retinoschisis. With increased cellular material the reflectivity increases, and thus serous fluid is optically transparent and appears dark on OCT, haemorrhage is hyper-reflective and cloudy exudate, for example, from a vitelliform lesion, is intermediate in reflectivity.

\section{Macular holes}

Although the diagnosis of established full-thickness macular holes usually presents little problem biomicroscopically, OCT is useful in the differential diagnosis of stage 1 holes from other subtle spots at the macula, and also can unequivocally classify stage $2-4$ holes. Recent evidence from OCT studies has shed light on the pathogenesis and natural history of macular holes. ${ }^{21-23}$ Stage 1 or impending holes appear as varying degrees of hyporeflective, intrafoveal split with the posterior hyaloid visibly attached to the foveal centre (Figure 2c). The posterior hyaloid may then either separate with spontaneous regression of the foveal cyst ${ }^{24-}$ ${ }^{26}$ or separate along with a fragment of retina forming a lamellar hole. Alternatively, the cyst roof may open eccentrically with the hyaloid still attached, which, with opening of the foveal floor, results in full-thickness separation of the retina and the formation of a stage 2 hole (Figure 2d). In stage 3 holes the posterior hyaloid is completely detached from the fovea but still adherent to the optic disc, and in stage 4 holes it is totally separated from the posterior pole. An 'operculum' may be visible anterior to the hole on the posterior hyaloid. In terms of the vitreoretinal interface in the region of the macular hole, OCT has shown that there is no difference between the stage 3 and 4 holes diagnosed biomicroscopically. Note that the OCT appearances allow more accurate grading of stage 2 and 3 holes, hitherto arbitrarily differentiated on the basis of size $(300 \mu \mathrm{m}){ }^{27}$ In stage 3 and 4 holes, intraretinal oedema may be evident at the edges of the hole (Figure 2e).

Examination of the fellow eye may also be of prognostic value. If the posterior hyaloid is separated from the fovea, then a macular hole is most unlikely and follow-up is not necessary ${ }^{28,29}$ irrespective of whether or not a posterior vitreous detachment is apparent on biomicroscopy. If there is only a perifoveal posterior hyaloid separation or a stage 1 hole, then follow-up may be worthwhile. It may even be worth considering vitrectomy for stage 1 macular holes, and rather than separating the posterior hyaloid, the foveal attachment can be circumcised relieving the vitreoretinal traction and preventing hole formation.

Preoperatively, an OCT scan may show the presence of a coexisting epiretinal membrane (ERM), which might need to be peeled during vitrectomy (Figure 2f). The membrane appears as a hyper-reflective (red) layer on the surface of the retina, and sometimes it is partially separated from the retina, aiding diagnosis (see below). At present the technology does not resolve the internal limiting membrane as a discrete layer. Postoperatively, OCT will clearly demonstrate the extent of hole closure. Usually there is complete hole closure with return of the normal foveal contour, but sometimes the retina flattens without apposition of the adjacent edges of the hole..$^{30,31}$ Whether a hole is flat but not closed, or whether there is some subretinal fluid persisting, may influence the decision to reoperate. 
In a rhegmatogenous retinal detachment, the macula may become cystic and the appearances may be very difficult to differentiate from a macular hole.

Alternatively, a full-thickness macular hole may accompany a retinal detachment as either the primary or secondary break. Providing the macula is not hidden by the related retinal detachment, OCT will usually demonstrate a full-thickness defect if a macular hole is present thus allowing planning of internal drainage.

\section{Lamellar holes}

Lamellar holes usually result from rupture of a macular cyst. OCT shows a partial-thickness retinal defect, with concave lateral edges to the hole, and a layer of outer retina in its base (Figure $2 \mathrm{~g}$ ). Sometimes, the roof of a lamellar hole is present to some extent, opening into the vitreous cavity. The overall central retinal thickness is usually increased or may be normal, but reduced in the region of the hole. This is in contrast to the appearances of a pseudohole, which is a defect in an ERM; here the retinal layer appears to be of increased thickness, whereas the retina in the region of the hole is of normal thickness.

\section{Epiretinal membranes/pseudoholes}

ERMs appear as a highly reflective (red) layer on the surface of the retina. Thin membranes may be difficult to differentiate from the normal nerve fibre layer, but are readily identifiable if the overall retinal thickness is increased, or if the membrane is partially separated from the retina at one or more points (Figure $2 \mathrm{~h}$ ). The latter feature is also useful in planning surgery, by demonstrating a possible site of access to the correct surgical plane. ${ }^{32}$ Other factors such as retinal distortion, associated macular oedema, and tractional retinal detachment may all be demonstrated. The increase in macular thickness has been found to correlate with visual acuity. ${ }^{33}$ Differentiation of a partially adherent ERM from a partially separated posterior hyaloid is important, and can usually be made on OCT: the hyper-reflective signal from the posterior hyaloid is thinner and often more patchy than that from an ERM, which is of greater thickness.

\section{Vitreomacular traction syndrome}

Vitreomacular traction (VMT) syndrome occurs when the posterior hyaloid partially separates from the retina but remains tightly adherent to the fovea thereby exerting traction (Figure 3a). It is often, but not always, associated with an ERM. OCT can show the resulting change in retinal contour as a consequence of the traction, as well as any membrane, and is useful diagnostically. Vitrectomy is often beneficial, but spontaneous resolution of VMT has also been demonstrated by OCT. ${ }^{34,35}$

\section{Central serous retinopathy}

On OCT, central serous retinopathy appears as an elevation of the full-thickness neurosensory retinal layer from the highly reflective RPE layer, separated by an optically empty zone (Figure $3 b$ ). A defect in the RPE may be demonstrated, potentially the point of leakage, as may any associated pigment epithelial detachment. ${ }^{36}$ Sometimes the elevated photoreceptor layer becomes more hyper-reflective resulting in an additional red signal at the outer border of the retina, a potentially confusing artefact due to the altered contour of the photoreceptors. The detached neurosensory retina is also thickened in comparison to the retinal thickness in the same region once the CSR has resolved. ${ }^{37}$ While the CSR lesion is usually diagnosed biomicroscopically, OCT allows measurement of the height of the serous detachment, which is potentially useful for follow-up, and may also demonstrate small CSR lesions which are not visible directly. It also obviates the need for fluorescein angiography, unless the CSR lesion fails to resolve spontaneously and laser treatment may be indicated.

\section{Macular oedema}

Macular oedema is a condition in which OCT carries one of its greatest clinical applications. Macular oedema occurs in a range of conditions including diabetes mellitus, following cataract surgery ${ }^{38}$ or retinal vein occlusion, and in association with uveitis, macular holes, and ERMs. On OCT, macular oedema appears as a collection of hyporeflective spaces within the retina, with overall macular thickening and usually a loss of the foveal depression (Figure 3c). Serial OCT examination allows more accurate qualitative follow-up of the changes in retinal profile than biomicroscopy alone, and extending this to retinal thickness measurement ${ }^{20,39,40}$ or mapping, an objective quantitative assessment of small changes during follow-up is possible. ${ }^{41}$

Fluorescein angiography is extremely useful in demonstrating macular oedema, but it is qualitative and dependent on the source of leakage persisting in order for the dye to leak into the area of oedema to highlight it. OCT on the other hand shows the oedema that is present whether the focus is still leaking or not and is also quantitative. The radial line option on the OCT software takes six radially disposed scans centred on fixation, and thus the retinal thickness can be calculated for 600 macular points. The software allows for a false-colour 

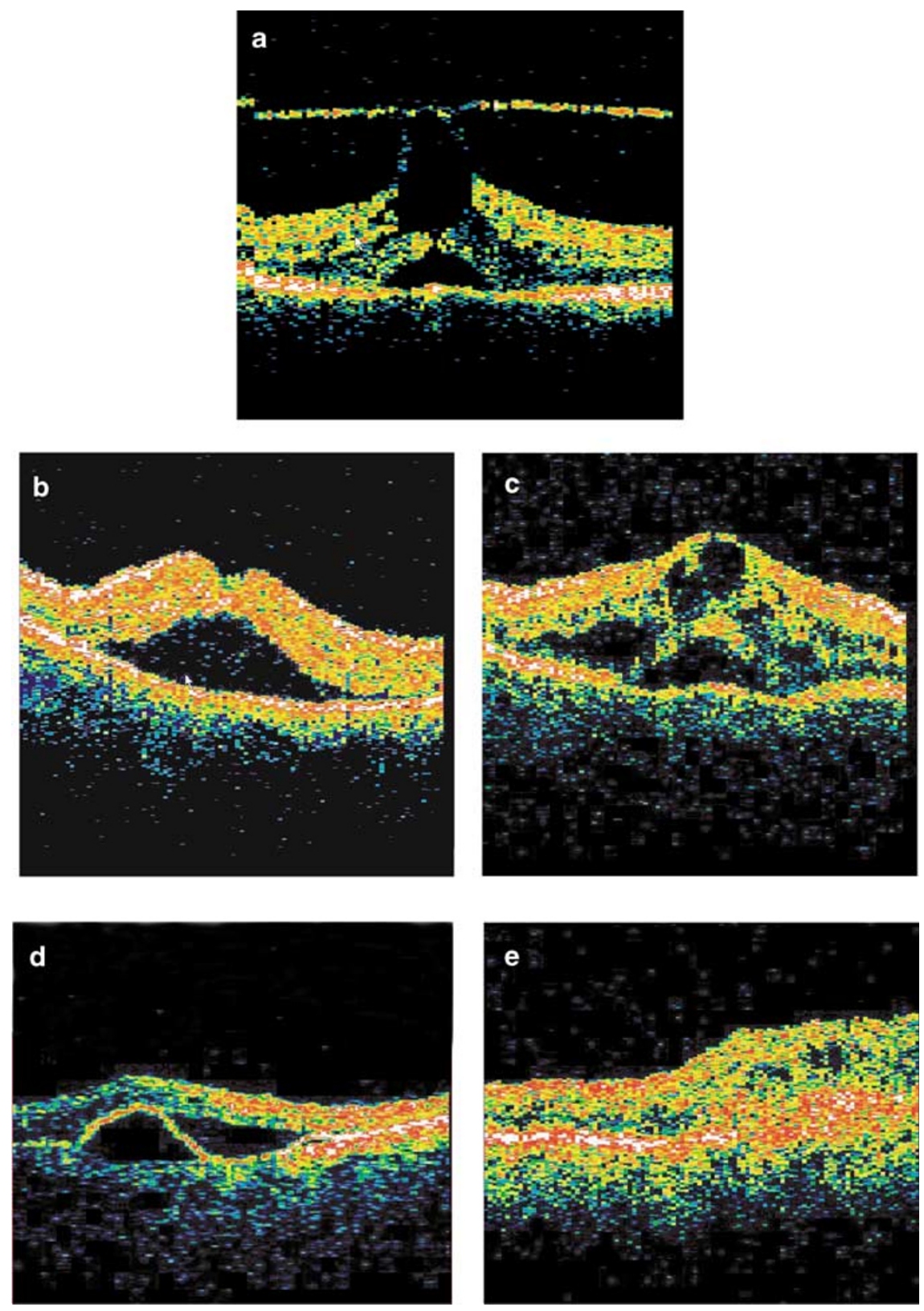

Figure 3 (a) Vitreomacular traction syndrome. OCT shows the posterior hyaloid tightly adherent to the edge of the fovea exerting traction and distorting the retinal contour. (b) Central serous retinopathy appears as an elevation of the full-thickness neurosensory retinal layer from the highly reflective RPE layer, separated by an optically empty zone. (c) Cystoid macular oedema. OCT shows multiple hyporeflective spaces within the retina, overall macular thickening, and loss of the foveal depression. (d) Serous PED with RPE elevation and no masking of the underlying choroid. (e) CNV appears as thickening of the RPE layer.

retinal map to be reconstructed from the data, enabling the average thickness to be displayed in each of nine macular zones, and also a calculation of the macular volume. Thus a quantitative assessment can be made allowing longitudinal follow-up for assessment of spontaneous resolution or response to any treatment. The measurement of central foveal thickness in macular oedema correlates, albeit weakly, with the reduction in vision. ${ }^{16}$
OCT also has an advantage over fluorescein angiography in being able to image the Z-plane in addition to the $X-Y$-plane. A recent study showed OCT to be highly sensitive (96\%) and specific (100\%) in the detection of oedema in patients with uveitis, more sensitive than both biomicroscopy alone and fluorescein angiography. ${ }^{42} Z$-plane imaging is also useful in describing the morphological appearance of diffuse diabetic macular oedema. A recent OCT study has shown 
two patterns of diabetic macular oedema, that is, a domed appearance where the fluid everts the fovea and a diffuse appearance where the inner retinal contour is flat. ${ }^{43}$ Another study describes three patterns of intraretinal oedema in diabetic patients: sponge-like retinal swelling, which occurred most commonly, cystoid macular oedema and serous retinal detachment, which may coexist with either of the first two patterns. ${ }^{44}$

\section{Retinoschisis or retinal detachment?}

The differentiation between a chronic retinal detachment and a retinoschisis is sometimes very difficult biomicroscopically. The resolution of OCT usually renders apparent the partial-thickness retinal separation of a retinoschisis compared with the full-thickness neurosensory retinal detachment. ${ }^{45}$ In the schisis, a moderately reflective (usually green) band is visible anterior to the RPE. However, the peripheral viewing of OCT is limited to about $30^{\circ}$, and sometimes the outer leaf of a schisis is very thin and not always detectable. If retinal detachment surgery is required, OCT can demonstrate the presence and extent of any vitreous detachment, which may influence the choice of an internal or external surgical approach.

A recent study has demonstrated three distinct appearances of the paramacular retinal structure on OCT in rhegmatogenous retinal detachment. ${ }^{46}$ The detached neurosensory retina may be of otherwise normal thickness and appearance, it may show intraretinal separation on either side of the fovea, or intraretinal separation may be present associated with undulation of the outer retinal layer. The latter two appearances were associated with poor best-corrected visual acuity, along with height of the detachment. Wolfensberger et al ${ }^{47}$ have demonstrated that a subfoveal cyst may be one cause of a failure of improvement in visual acuity following successful retinal detachment surgery. OCT may also be useful in the differentiation of macular schisis, a recently revisited concept described in high myopes, from macular oedema. ${ }^{21,48}$

\section{Age-related macular degeneration}

The varying appearances of the wide range of lesions seen in ARMD have been beautifully illustrated by Hee et al. ${ }^{49}$ Soft drusen appear as elevations of the highly reflective RPE layer, consistent with excrescences in Bruch's membrane. These lesions do not however shadow the return from the choroid. RPE hyperpigmentation, however, shows increased reflectivity and a degree of masking of the deeper choroidal layers. The window defect of RPE atrophy shows highly reflective backscatter from choroid due to increased penetration of the signal. In RPE detachments (PED), elevation of the RPE is apparent. Masking of the underlying choroid is seen in fibrovascular and haemorrhagic PED and not with serous PED (Figure 3d). Any associated intraretinal oedema appears as cystic spaces within the retina, and a coexisting neurosensory detachment may be present. An RPE tear can be seen as loss of the normal dome-shaped profile of the RPE in a PED, with hyper-reflectivity adjacent to the folded RPE. ${ }^{50}$ Choroidal neovascularisation (CNV) appears as thickening of the RPE layer (Figure 3e). With classic membranes the RPE layer shows more fusiform thickening, whereas occult membranes are more irregular and variable in cross-sectional appearance. CNV deep to RPE detachments is not usually visible.

The appearances of neovascularisation on OCT are not as useful as fluorescein angiography with respect to planning laser treatment: they are not as specific and the plan view of the angiogram delineates the location and extent of the membrane more intuitively in the same plane. However, any change or resolution of oedema following treatment is apparent and OCT has been used to monitor the retinal changes that occurred following photodynamic therapy in patients with $\mathrm{CNV} .{ }^{51,52}$ Retinal laser scars appear as areas of increased reflectivity of the outer retinal layers with surrounding areas of lower reflectivity. ${ }^{53}$

\section{Optic disc lesions}

The scan pattern can be selected to perform an annular scan around the disc thereby permitting measurement of nerve fibre layer (RNFL) thickness. This has been found to be reproducible in normal and glaucomatous eyes, and correlates with the visual field loss. ${ }^{54,55}$ It has potential use for the diagnosis of early glaucoma, but is not yet commonplace. However, two recent masked comparisons of nerve fibre layer thickness, one comparing thickness measured by scanning laser polarimetry and $\mathrm{OCT}^{56}$ and the other comparing Heidelberg retinal tomography and OCT, showed that both techniques were capable of differentiating glaucomatous from nonglaucomatous eyes, but neither was sensitive enough to differentiate normal eyes from eyes with ocular hypertension. The latter study also showed that fixation using the eye being studied was more reproducible than fixation using the contralateral eye. Another study found a difference between normal and ocular hypertensive eyes in the inferior and nasal quadrants. ${ }^{57}$ OCT measurement of RNFL thickness also correlated well with the global indices of visual function on the visual field analysis.

The presence of optic nerve head drusen has been correlated with nerve fibre layer thinning and the 
associated visual field defects, ${ }^{58}$ and it has been suggested that RNFL measurement may be useful in following patients with coexisting optic nerve head drusen and glaucoma. ${ }^{59}$

Other anomalous disc appearances such as glaucomatous cupping and papilloedema can be imaged and quantified. OCT has also clearly demonstrated the communication between an optic disc pit and the schisis cavity or subretinal space present at the macula. ${ }^{60,61}$ Improvement of vision with pneumatic retinopexy has been shown to be associated with flattening of the serous neurosensory retinal detachment, but the macular schisis persists. $^{62}$

\section{Conclusion}

In many macular conditions, OCT may be diagnostic and used as a noninvasive alternative to fluorescein angiography. However, even in conditions that are readily diagnosed biomicroscopically, such as CSR and oedema secondary to retinal vein occlusion, the objective serial quantitative measurement offered by OCT is of value in follow-up since treatment is variably effective and difficult to assess biomicroscopically. As with many medical investigations, the examiner can often produce a more fruitful and more detailed report if he or she has an idea of what to look for in the way of a synopsis from the requesting clinician. As more units are installed around the country, the benefits of the easily interpretable OCT images should become available to more clinicians.

\section{References}

1 Hee MR, Izatt JA, Swanson EA, Huang D, Schuman JS, Lin $\mathrm{CP}$ et al. Optical coherence tomography of the human retina. Arch Ophthalmol 1995; 113: 325-332.

2 Feng Y, Varikooty J, Simpson TL. Diurnal variation of corneal and corneal epithelial thickness measured using optical coherence tomography. Cornea 2001; 20: 480-483.

3 Muscat S, McKay N, Parks S, Kemp E, Keating D. Repeatability and reproducibility of corneal thickness measurements by optical coherence tomography. Invest Ophthalmol Vis Sci 2002; 43: 1791-1795.

4 Radhakrishnan S, Rollins AM, Roth JE, Yazdanfar S, Westphal V, Bardenstein DS, Izatt JA. Real-time optical coherence tomography of the anterior segment at $1310 \mathrm{~nm}$. Arch Ophthalmol 2001; 119: 1179-1185.

5 Pitris C, Brezinski ME, Bouma BE, Tearney GJ, Southern JF, Fujimoto JG. High resolution imaging of the upper respiratory tract with optical coherence tomography: a feasibility study. Am J Respir Crit Care Med 1998; 157: 1640-1644.

6 Boppart SA, Goodman A, Libus J, Pitris C, Jesser CA, Brezinski ME et al. High resolution imaging of endometriosis and ovarian carcinoma with optical coherence tomography: feasibility for laparoscopic-based imaging. Br J Obstet Gynaecol 1999; 106: 1071-1077.
7 Jesser CA, Boppart SA, Pitris C, Stamper DL, Nielsen GP, Brezinski ME et al. High resolution imaging of transitional cell carcinoma with optical coherence tomography: feasibility for the evaluation of bladder pathology. $\mathrm{Br} J$ Radiol 1999; 72: 1170-1176.

8 Kobayashi K, Izatt JA, Kulkarni MD, Willis J, Sivak Jr MV. High-resolution cross-sectional imaging of the gastrointestinal tract using optical coherence tomography: preliminary results. Gastrointest Endosc 1998; 47: 515-523.

9 Brezinski ME, Tearney GJ, Bouma BE, Izatt JA, Hee MR, Swanson EA et al. Optical coherence tomography for optical biopsy. Properties and demonstration of vascular pathology. Circulation 1996; 93: 1206-1213.

10 Tearney GJ, Brezinski ME, Bouma BE, Boppart SA, Pitris C, Southern JF et al. In vivo endoscopic optical biopsy with optical coherence tomography. Science 1997; 276: 2037-2039.

11 Huang D, Swanson EA, Lin CP, Schuman JS, Stinson WG, Chang W et al. Optical coherence tomography. Science 1991; 254: 1178-1181.

12 Drexler W, Morgner U, Ghanta RK, Kartner FX, Schuman JS, Fujimoto JG. Ultrahigh-resolution ophthalmic optical coherence tomography. Nat Med 2001; 7: 502-507.

13 Gloesmann M, Hermann B, Schubert C, Sattmann H, Ahnelt PK, Drexler W. Histologic correlation of pig retina radial stratification with ultrahigh-resolution optical coherence tomography. Invest Ophthalmol Vis Sci 2003; 44: 1696-1703.

14 Chauhan DS, Marshall J. The interpretation of optical coherence tomography images of the retina. Invest Ophthalmol Vis Sci 1999; 40: 2332-2342.

15 Toth CA, Narayan DG, Boppart SA, Hee MR, Fujimoto JG, Birngruber $\mathrm{R}$ et al. A comparison of retinal morphology viewed by optical coherence tomography and by light microscopy. Arch Ophthalmol 1997; 115: 1425-1428.

16 Hee MR, Puliafito CA, Duker JS, Reichel E, Coker JG, Wilkins JR et al. Topography of diabetic macular edema with optical coherence tomography. Ophthalmology 1998; 105: 360-370.

17 Massin P, Erginay A, Haouchine B, Mehidi AB, Paques M, Gaudric A. Retinal thickness in healthy and diabetic subjects measured using optical coherence tomography mapping software. Eur J Ophthalmol 2002; 12: 102-108.

18 Puliafito CA, Hee MR, Lin CP, Reichel E, Schuman JS, Duker JS et al. Imaging of macular diseases with optical coherence tomography. Ophthalmology 1995; 102: 217-229.

19 Hee MR, Puliafito CA, Wong C, Duker JS, Reichel E, Schuman JS et al. Optical coherence tomography of macular holes. Ophthalmology 1995; 102: 748-756.

20 Massin P, Vicaut E, Haouchine B, Erginay A, Paques M, Gaudric A. Reproducibility of retinal mapping using optical coherence tomography. Arch Ophthalmol 2001; 119: 1135-1142.

21 Gaudric A, Haouchine B, Massin P, Paques M, Blain P, Erginay A. Macular hole formation: new data provided by optical coherence tomography. Arch Ophthalmol 1999; 117: 744-751.

22 Tanner V, Chauhan DS, Jackson TL, Williamson TH. Optical coherence tomography of the vitreoretinal interface in macular hole formation. Br J Ophthalmol 2001; 85: 1092-1097.

23 Chauhan DS, Antcliff RJ, Rai PA, Williamson TH, Marshall J. Papillofoveal traction in macular hole formation: the role of optical coherence tomography. Arch Ophthalmol 2000; 118: 32-38.

24 Takahashi H, Kishi S. Optical coherence tomography images of spontaneous macular hole closure. Am J Ophthalmol 1999; 128: $519-520$. 
25 Ebato K, Kishi S. Spontaneous closure of macular hole after posterior vitreous detachment. Ophthalmic Surg Lasers 2000; 31: 245-247.

26 Yamada H, Sakai A, Yamada E, Nishimura T, Matsumura M. Spontaneous closure of traumatic macular hole. Am J Ophthalmol 2002; 134: 340-347.

27 Gass JD. Reappraisal of biomicroscopic classification of stages of development of a macular hole. Am J Ophthalmol 1995; 119: 752-759.

28 Hikichi T, Akiba J, Trempe CL. Effect of the vitreous on the prognosis of full-thickness idiopathic macular hole. Am J Ophthalmol 1993; 116: 273-278.

29 Akiba J, Quiroz MA, Trempe CL. Role of posterior vitreous detachment in idiopathic macular holes. Ophthalmology 1990; 97: 1610-1613.

30 Mikajiri K, Okada AA, Ohji M, Morimoto T, Sato S, Hayashi A et al. Analysis of vitrectomy for idiopathic macular hole by optical coherence tomography. Am J Ophthalmol 1999; 128: 655-657.

31 Imai M, Iijima H, Gotoh T, Tsukahara S. Optical coherence tomography of successfully repaired idiopathic macular holes. Am J Ophthalmol 1999; 128: 621-627.

32 Azzolini C, Patelli F, Codenotti M, Pierro L, Brancato R. Optical coherence tomography in idiopathic epiretinal macular membrane surgery. Eur J Ophthalmol 1999; 9: 206-211.

33 Wilkins JR, Puliafito CA, Hee MR, Duker JS, Reichel E, Coker JG et al. Characterization of epiretinal membranes using optical coherence tomography. Ophthalmology 1996; 103: 2142-2151.

34 Sulkes DJ, Ip MS, Baumal CR, Wu HK, Puliafito CA. Spontaneous resolution of vitreomacular traction documented by optical coherence tomography. Arch Ophthalmol 2000; 118: 286-287.

35 Munuera JM, Garcia-Layana A, Maldonado MJ, Aliseda D Moreno-Montanes J. Optical coherence tomography in successful surgery of vitreomacular traction syndrome. Arch Ophthalmol 1998; 116: 1388-1389.

36 Hee MR, Puliafito CA, Wong C, Reichel E, Duker JS, Schuman JS et al. Optical coherence tomography of central serous chorioretinopathy. Am J Ophthalmol 1995; 120: 65-74

37 Iida T, Hagimura N, Sato T, Kishi S. Evaluation of central serous chorioretinopathy with optical coherence tomography. Am J Ophthalmol 2000; 129: 16-20.

38 Sourdille P, Santiago PY. Optical coherence tomography of macular thickness after cataract surgery. J Cataract Refract Surg 1999; 25: 256-261.

39 Baumann M, Gentile RC, Liebmann JM, Ritch R. Reproducibility of retinal thickness measurements in normal eyes using optical coherence tomography. Ophthalmic Surg Lasers 1998; 29: 280-285.

40 Muscat S, Parks S, Kemp E, Keating D. Repeatability and reproducibility of macular thickness measurements with the Humphrey OCT system. Invest Ophthalmol Vis Sci 2002; 43: 490-495.

41 Hee MR, Puliafito CA, Wong C, Duker JS, Reichel E, Rutledge B et al. Quantitative assessment of macular edema with optical coherence tomography. Arch Ophthalmol 1995; 113: 1019-1029.

42 Antcliff RJ, Stanford MR, Chauhan DS, Graham EM, Spalton DJ, Shilling JS et al. Comparison between optical coherence tomography and fundus fluorescein angiography for the detection of cystoid macular edema in patients with uveitis. Ophthalmology 2000; 107: 593-599.
43 Massin P, Duguid G, Erginay A, Haouchine B, Gaudric A. Optical coherence tomography for evaluating diabetic macular edema before and after vitrectomy. Am J Ophthalmol 2003; 135: 169-177.

44 Otani T, Kishi S, Maruyama Y. Patterns of diabetic macular edema with optical coherence tomography. Am J Ophthalmol 1999; 127: 688-693.

45 Ip M, Garza-Karren C, Duker JS, Reichel E, Swartz JC, Amirikia A et al. Differentiation of degenerative retinoschisis from retinal detachment using optical coherence tomography. Ophthalmology 1999; 106: 600-605.

46 Hagimura N, Suto K, Iida T, Kishi S. Optical coherence tomography of the neurosensory retina in rhegmatogenous retinal detachment. Am J Ophthalmol 2000; 129: 186-190.

47 Wolfensberger TJ, Gonvers M. Optical coherence tomography in the evaluation of incomplete visual acuity recovery after macula-off retinal detachments. Graefes Arch Clin Exp Ophthalmol 2002; 240: 85-89.

48 Benhamou N, Massin P, Haouchine B, Erginay A, Gaudric A. Macular retinoschisis in highly myopic eyes. Am J Ophthalmol 2002; 133: 794-800.

49 Hee MR, Baumal CR, Puliafito CA, Duker JS, Reichel E, Wilkins JR et al. Optical coherence tomography of agerelated macular degeneration and choroidal neovascularization. Ophthalmology 1996; 103: 1260-1270.

50 Giovannini A, Amato G, Mariotti C, Scassellati-Sforzolini B. Optical coherence tomography in the assessment of retinal pigment epithelial tear. Retina 2000; 20: 37-40.

51 Costa RA, Farah ME, Cardillo JA, Belfort Jr R. Photodynamic therapy with indocyanine green for occult subfoveal choroidal neovascularization caused by age-related macular degeneration. Curr Eye Res 2001; 23 : 271-275.

52 Rogers AH, Martidis A, Greenberg PB, Puliafito CA. Optical coherence tomography findings following photodynamic therapy of choroidal neovascularization. Am J Ophthalmol 2002; 134: 566-576.

53 Toth CA, Birngruber R, Boppart SA, Hee MR, Fujimoto JG, DiCarlo CD et al. Argon laser retinal lesions evaluated in vivo by optical coherence tomography. Am J Ophthalmol 1997; 123: 188-198.

54 Schuman JS, Hee MR, Puliafito CA, Wong C, PedutKloizman T, Lin CP et al. Quantification of nerve fiber layer thickness in normal and glaucomatous eyes using optical coherence tomography. Arch Ophthalmol 1995; 113: 586-596.

55 Pieroth L, Schuman JS, Hertzmark E, Hee MR, Wilkins JR, Coker J et al. Evaluation of focal defects of the nerve fiber layer using optical coherence tomography. Ophthalmology 1999; 106: 570-579.

56 Hoh ST, Greenfield DS, Mistlberger A, Liebmann JM, Ishikawa H, Ritch R. Optical coherence tomography and scanning laser polarimetry in normal, ocular hypertensive, and glaucomatous eyes. Am J Ophthalmol 2000; 129: 129-135.

57 Bowd C, Weinreb RN, Williams JM, Zangwill LM. The retinal nerve fiber layer thickness in ocular hypertensive, normal, and glaucomatous eyes with optical coherence tomography. Arch Ophthalmol 2000; 118: 22-26.

58 Roh S, Noecker RJ, Schuman JS, Hedges III TR, Weiter JJ, Mattox C. Effect of optic nerve head drusen on nerve fiber layer thickness. Ophthalmology 1998; 105: 878-885.

59 Roh S, Noecker RJ, Schuman JS. Evaluation of coexisting optic nerve head drusen and glaucoma with optical coherence tomography. Ophthalmology 1997; 104: $1138-1144$. 
60 Rutledge BK, Puliafito CA, Duker JS, Hee MR, Cox MS Optical coherence tomography of macular lesions associated with optic nerve head pits. Ophthalmology 1996; 103: 1047-1053.

61 Krivoy D, Gentile R, Liebmann JM, Stegman Z, Rosen $\mathrm{R}$, Walsh JB et al. Imaging congenital optic disc pits and associated maculopathy using optical coherence tomography. Arch Ophthalmol 1996; 114: $165-170$.

62 Lincoff H, Kreissig I. Optical coherence tomography of pneumatic displacement of optic disc pit maculopathy. $\mathrm{Br} \mathrm{J}$ Ophthalmol 1998; 82: 367-372. 